\title{
Evaluation of the Prevalence of Clinical Consequences of Untreated Dental Caries Using PUFA/pufa Index in a Group of Iranian Children
}

\author{
Nahid Ramazani, ${ }^{1, *}$ and Sara Rezaei ${ }^{2}$ \\ ${ }^{1}$ Children and Adolescents Health Research Center, Oral and Dental Disease Research Center, Pediatric Dentistry Department, Zahedan University of Medical Sciences, \\ Zahedan, IR Iran \\ ${ }^{2}$ Zahedan University of Medical Sciences, Zahedan, IR Iran
}

"Corresponding author: Nahid Ramazani, Department of Pediatric Dentistry, School of Dentistry, Zahedan University of Medical Sciences, Azadegan St., Khorramshahr Ave., Zahedan, IR Iran. Tel: +98-5433414005, Fax: +98-5433414003, E-mail: ramazani_nahid@yahoo.com

Received 2015 December 10; Revised 2016 June 20; Accepted 2016 August 01.

\begin{abstract}
Background: Untreated dental caries have considerable consequences on the growth and development of children and their quality of life.

Objectives: The aim of this study was to evaluate the prevalence of clinical consequences of untreated dental caries in a sample of Iranian children based on the pufa/PUFA diagnostic index.

Methods: In this descriptive analytical study, 360 students between the ages of 6 - 12 years were selected using cluster sampling. Oral clinical examinations were performed by one pedodontist. DMFT, dmft, PUFA and pufa scores were recorded. The height and weight of children were also measured to calculate body mass index (BMI). Descriptive findings are reported in terms of frequencies and percentages, as well as means and standard deviations. The data were analyzed in the Statistical Package for the Social Sciences (SPSS) version 21 using Fisher's Exact Test, the Mann Whitney U test, and logistic regression. The level of significance was set at $\mathrm{P}=$ 0.05 .

Results: The overall caries experience and the overall prevalence of untreated dental caries in the study population was $93.0 \%$ (mean value of $4.39 \pm 2.78$ ) and $30.0 \%$ (mean value of $0.57 \pm 1.15$ ), respectively. Components of $\mathrm{d} / \mathrm{D}$ and $\mathrm{p} / \mathrm{P}$ had the highest frequencies. Males and females showed no significant differences in terms of prevalence or severity of untreated dental caries $(\mathrm{P}>0.05)$. The prevalence and mean value of pufa score were significantly higher in under-weight subjects than in normal children $(\mathrm{P}<0.05)$. Under-weight subjects had 10 and 3.5 times greater risk of pufa and PUFA development, respectively.
\end{abstract}

Conclusions: Our results emphasize the need for further attention to public dental care programs and dental care measures.

Keywords: Dental Caries, pufa/PUFA Index, Children

\section{Background}

In developing countries, most dental caries remain untreated, and many children suffer from its consequences (1, 2 ). The effects of untreated caries have been evaluated in many studies $(1,3,4)$. Untreated caries can cause changes in the health status, quality of life, growth, developmental patterns, and school performance of children; in severe cases, it can cause cellulitis or even brain abscess $(1,3,5)$.

The dmft/DMFT index is used for the assessment of dental status in different communities and age groups. However, this index does not provide any information regarding the consequences of untreated caries; it only evaluates the presence of caries, restorations, and missing teeth (2). Pulpal involvement as a consequence of dental caries is not taken into account in this index. In 2010, a new index referred to as pufa/PUFA was introduced to determine the frequency and the severity of the clinical consequences of untreated caries (2). In this index, exposed pulp, oral mucosal wounds due to remaining roots, fistula, and abscess are reported. This index has been used in only a few studies on Brazilian and Filipino children $(1,6,7)$. Some previous studies have evaluated the dental status of Iranian children, and all of them have used the classic dmft/DMFT in$\operatorname{dex}(8-11)$.

In a study by Monse et al. in 2010, the pufa and PUFA indices for 6 - 12-year-old Filipino children were reported to be 3.5 and 1.2, respectively (2). In addition, in 2013, Oziegbe et al. evaluated the frequency and clinical consequences of untreated caries in Nigerian elementary school children using the pufa index (12). Moreover, in 2012, Baginska et al. evaluated the efficacy of the pufa index in detecting the consequences of untreated caries in primary dentition of children in Poland and reported a strong association between the dmft and pufa indices (13). In their study in Brazil in 2011, Figueiredo et al. reported pufa to be a suitable epidemiologic index for the assessment of dental caries (6). 


\section{Objectives}

No previous study has evaluated the frequency of pufa/PUFA in Iran. This index can be largely used for dental treatment planning, emergency dental treatments and evaluation of the accessibility of dental care services; it may even be superior to $\mathrm{dmft} / \mathrm{DMFT}$ in this regard. Considering all of the above, this study aimed to assess the prevalence of the clinical consequences of untreated dental caries in a group of 6 -12-year-old Iranian children as detected by pufa/PUFA.

\section{Methods}

This descriptive analytical study was approved by the Ethics Committee of Zahedan University of Medical Sciences (code 92-186). A total of 360 students between 6 - 12 years old were selected from 4 elementary schools in 2 city districts (I and II) of Zahedan in southeast Iran using cluster sampling in January, 2014. According to a pilot study, the sample size was calculated to be 323 subjects $(z=1.96$, $\mathrm{P}=0.3, \mathrm{~d}=0.05)$. To obtain more reliable results, we enrolled 360 subjects in our study. To minimize the effect of socioeconomic status, a public (boys-only) and a private (girls-only) school were randomly selected from district I and a public (girls-only) and a private (boys-only) school were randomly selected from district II. Stratified cluster sampling was used in all schools in such a way that fifteen subjects were randomly selected from the list of students in one randomly selected class in each of the first to sixth grades. Generalized developmental dental anomalies or chronic diseases affecting oral and dental health were the exclusion criteria.

Parents of the chosen children gave their written informed consent for participation of their children in this study. Clinical examinations were then performed. Clinical examination was performed by an experienced pedodontist and DMFT, dmft, pufa, and PUFA indices were recorded. Photographs of 23 cases showing different parameters of pufa/PUFA (p/P, u/U, f/F, a/A) together with 30 non- pufa/PUFA cases were used to made the examiner calibrated. After a 1-month interval, the intra-examiner reliability was confirmed by re-examination of $10 \%$ of the study population.

PUFA/pufa is an index for recording the oral status and consequences of untreated caries. PUFA/pufa assessment was performed visually using a dental mirror without any instrumentation. Only one score was recorded per tooth. In PUFA/pufa, $\mathrm{P} / \mathrm{p}$ represents visible pulpal involvement of the severely decayed tooth (the pulp chamber is visibly exposed or the tooth crown is severely damaged due to extensive caries with only the roots or root segments remain- ing), whereas $\mathrm{U} / \mathrm{u}$ represents oral mucosal ulcerations due to trauma caused by the sharp tips of a carious tooth or the residual root segments; $\mathrm{F} / \mathrm{f}$ represents fistula, and A/a represents abscess. The PUFA/pufa index was calculated for each individual, similar to the DMFT/dmft, and indicates the number of teeth that meet the PUFA/pufa diagnostic criteria. The prevalence of PUFA/pufa was defined as the percentage of individuals with a PUFA/pufa score of one or more. The DMFT and dmft indices were also calculated and recorded according to the World Health Organization (WHO) criteria.

The reproducibility of PUFA/pufa and DMFT/dmft was assessed by re-examining $10 \%$ of the study population after 4 weeks. Prior to examination, all children were asked to brush their teeth. Clinical examination was performed in the health rooms of the schools, and children were examined in a supine position under daylight using a headlight. A dental explorer and a dental mirror were used to determine the DMFT/dmft index. Anthropometric measurements, including height and weight, were made by the health instructor of children. Measurements were repeated twice, and the mean values were recorded. Weight was measured using a digital scale with $100 \mathrm{~g}$ accuracy (Beurer $^{\circledR}$, Germany), which was calibrated after every five measurements. Measurements were made with children wearing light clothing in a standing position with no shoes on.

Height was measured using a tape measure (Stature ${ }^{\circledR}$ meter $2 \mathrm{~m}$, Germany) with $0.5 \mathrm{~cm}$ accuracy while children standing that was accurate to within children standing with no shoes on and their shoulders placed against the wall. Weight and height were used to calculate BMI (weight in $\mathrm{Kg} /$ height in $\mathrm{m}^{2}$ ). According to WHO guidelines, subjects were categorized into 4 groups in terms of BMI: underweight for age $(\mathrm{BMI}<13.25)$, normal weight for age $(\mathrm{BMI}=$ 13.25 - 17.5), over-weight for age (BMI =17.5 -18.5), and obese for age (BMI > 18.5). In addition, the dental health status of the children was recorded on forms, which were later given to parents to inform them about the dental health status of their children so that they could seek any necessary treatment.

Descriptive data were reported in terms of frequency and percentage, as well as mean and standard deviation values. Data were analyzed using Fisher's Exact Test, the Mann Whitney U test, and logistic regression in SPSS version 21 (Microsoft, IL, USA). The level of significance was set at $\mathrm{P}=0.05$.

\section{Results}

In this survey, 360 children with the mean age of 9.79 \pm 1.57 years were examined. Intra-examiner reliability was 
determined by re-examining $10 \%$ of the subjects throughout the survey using the kappa coefficient. The variations in kappa coefficient values for pufa, PUFA, dmft and DMFT were 0.81 to 0.89 , which can be interpreted as good.

Table 1 presents data regarding the prevalence, mean, and range of indices in the subject; detailed information in terms of gender and BMI are illustrated in Table 2.

The overall caries experience $(\mathrm{dmft}+$ DMFT $>0)$ was 93.0\%, and the overall prevalence of untreated dental caries (pufa + PUFA > 0) was 30.0\%. The mean values of these two indices were $4.39 \pm 2.78$ and $0.57 \pm 1.15$, respectively.

The main component of the dmft and DMFT indices was $d / D(d=77.6 \%$, $D$ 40.8\%). The diagnosis of other components was as follows: $\mathrm{m}=24.1 \%, \mathrm{M}=0.3 \%, \mathrm{f}=17.8 \%$, and $\mathrm{F}=$ 6.8. The major contributors of pufa and PUFA indices were $\mathrm{p} / \mathrm{P}(\mathrm{p}=23.0 \%, \mathrm{P}=3.5 \%)$. The frequency of other individual parameters was $\mathrm{u}=0.0 \%, \mathrm{U}=0.0 \%, \mathrm{f}=0.8 \%, \mathrm{~F}=0.0, \mathrm{a}=5.7 \%$, $A=0.3$. The " $d+D$ to PUFA" ratio was nearly $30 \%$, showing a relatively high rate of untreated caries progression to pulp involvement.

In relation to gender, there was a significant difference detected only for DMFT, both for the prevalence (Fisher's exact test, $\mathrm{P}<0.001$ ) and the mean value (Mann Whitney $\mathrm{U}, \mathrm{P}<0.001)$, with a predominance of females. For other indices including dmft, pufa, PUFA, dmft + DMFT, and pufa + PUFA, females did not show any significant difference when compared to males ( $\mathrm{P}>0.05)$.

Because only 9 children in our study population were over-weight and none of the children were obese, the data related to normal weight and under-weight children were statistically analyzed. As presented in Table 3, the prevalence and mean value of DMFT and PUFA were not associated with BMI. Similarly, the prevalence of dmft + DMFT was not associated with BMI. On the contrary, other indices were related to BMI.

Comparing children in terms of pufa prevalence with reference to BMI, after age and gender adjustment, a logistic regression model showed that under-weight subjects were nearly 10 times more likely to suffer from dental disease than normal children. Moreover, the under-weight group were nearly 3.5 times more likely to develop the PUFA compared to normal group.

\section{Discussion}

Dental caries, the most prevalent childhood disease, remain a public health problem worldwide (12, 14-18) This study aimed to assess the prevalence of the clinical consequences of untreated dental caries as detected by pufa/PUFA in 6 - 12-year-old Iranian children.

In the current study, the overall dental caries experience was found to be $93.0 \%$. The overall prevalence of clini- cal consequences of untreated dental caries was 30.0\%. Our study was the first to assess the consequences of untreated dental caries in 6 -12-year-olds in Iran and showed that despite the high prevalence of dental caries experience, the prevalence of consequences of untreated dental caries was relatively low, with a severity of $0.52 \pm 1.09$ in primary teeth and $0.06 \pm 0.34$ in permanent teeth. In other words, one out of three individuals in our study population suffered from the clinical consequences of untreated carious teeth, requiring pulp therapy or tooth extraction.

The prevalence of untreated dental caries in the current study indicates a lack of access to dental care services, which along with the presence of risk factors of dental caries, lead to the progression of carious lesions to pulp involvement and other consequences. Negligence of parents with regard to seeking dental treatment is another reason for this finding (15). Dental-related fears and behavior problems can also lead to delays in seeking dental treatments and consequently result in caries progression and eventual consequences of untreated carious teeth $(19,20)$. In fact, children with these avoidance behaviors should be treated under general anesthesia (21).

The DMFT/dmft index does not show the severity of caries or their consequences (22). This means that DMFT/dmft data alone cannot inform health policy makers about the severity of caries and their consequences on general health and quality of life. Public health authorities' decisions are mainly influenced by in which information is presented to them (2). For this reason, in recent years, great emphasis has been placed on developing more sensitive diagnostic criteria to better differentiate among the different stages of caries progression (23). The need for data regarding the extent of carious lesions and their consequences led to the development of the PUFA/pufa index (2). The PUFA/pufa index provides accurate information about the stage of caries and the clinical consequences of untreated caries (12). This index was first used in the Philippines, and its validity and reliability have been confirmed (2). It is currently used to epidemiologically assess carious lesions and classify the consequences of untreated caries. The four stages of caries defined in this index are related to the general health status of individuals (2). This index is easy to use, fast, and safe; it doesn't require any equipment, and it can be used by individuals other than dentists as well. Moreover, it has good intra- and inter-examiner reliability $(2,12,24)$.

In fact, PUFA/pufa provides policy makers with complete information, especially when combined with DMFT/dmft. The PUFA/pufa index is also recommended for use in populations with high rates of dental caries who have no access to therapeutic and preventive measures (13, 24). 
Table 1. Prevalence, Mean Value, and Range of Indices in the Studied Subjects

\begin{tabular}{|c|c|c|c|}
\hline Index & Prevalence No. (\%) & $\operatorname{Mean}(\mathrm{SD})$ & Range \\
\hline dmft & $306(82.7)$ & $3.49(2.78)$ & $0-12$ \\
\hline DMFT & $158(42.7)$ & $0.92(1.31)$ & $0-7$ \\
\hline pufa & $96(25.9)$ & $0.52(1.09)$ & $0-7$ \\
\hline PUFA & $14(3.8)$ & $0.06(0.34)$ & $0-4$ \\
\hline
\end{tabular}

Table 2. Prevalence and Mean Value of Indices in Relation to Gender and BMI

\begin{tabular}{|c|c|c|c|c|c|}
\hline \multirow[t]{3}{*}{ Index } & \multicolumn{5}{|c|}{ Variables } \\
\hline & \multicolumn{2}{|c|}{ Gender } & \multicolumn{3}{|c|}{ BMI } \\
\hline & Female & Male & Under-weight & Normal & Over-weight \\
\hline \multicolumn{6}{|c|}{ Prevalence, No. (\%) } \\
\hline $\mathrm{dmft}$ & $155(50.6)$ & $151(49.4)$ & $258(84.0)$ & $43(14.0)$ & $6(2.0)$ \\
\hline DMFT & $100(63.3)$ & $58(36.7)$ & $119(75.3)$ & $36(22.8)$ & $3(1.9)$ \\
\hline pufa & $46(47.9)$ & $50(52.1)$ & $88(91.6)$ & $8(8.4)$ & $0(0.0)$ \\
\hline PUFA & $7(50.0)$ & $7(50.0)$ & $11(78.6)$ & $3(21.4)$ & $0(0.0)$ \\
\hline \multicolumn{6}{|l|}{ Mean (SD) } \\
\hline $\mathrm{dmft}$ & $3.44(2.82)$ & $3.54(2.74)$ & $4.05(2.76)$ & $1.45(1.67)$ & $0.89(1.05)$ \\
\hline DMFT & $1.25(1.48)$ & $0.58(1.00)$ & $0.87(1.29)$ & $1.14(1.37)$ & $0.89(1.53)$ \\
\hline pufa & $0.47(1.04)$ & $0.57(1.14)$ & $0.62(1.19)$ & $0.16(0.44)$ & $0(0)$ \\
\hline PUFA & $0.06(0.38)$ & $0.06(0.30)$ & $0.06(0.33)$ & $0.09(0.41)$ & $0(0)$ \\
\hline
\end{tabular}

Previous studies using PUFA/pufa are scarce, and there is limited relevant information in such studies. Unfortunately, direct comparison of our results with the results of these studies is not feasible due to differences in factors such as age, sex, ethnicity, and socio-economic status. However, some of these studies are discussed here. For example, Murthy et al. (19) and Oziegbe et al. (12) assessed the overall prevalence of untreated dental caries and reported values of $19.4 \%$ and $4.0 \%$, respectively, which are much lower than our obtained value. In addition to the known and unknown differences between the study populations, the higher prevalence of untreated caries in our study may be attributed to the higher dental caries experience compared to the corresponding value in the aforementioned studies (93.0\% versus $57.9 \%$ and $10.0 \%$, respectively).

On the other hand, Shanbhog et al. (22) reported the prevalence of untreated caries to be $37.7 \%$; this value was $55 \%$ in the studies conducted in the Philippines, $(1,2)$ which are both higher than our obtained value. In their study in Poland, Baginska and Stokowska (24) reported the frequency of untreated caries of primary teeth to be $40.77 \%$ in 6 - 8 year-olds with a mean value of $0.85 \pm 1.33$. In another study by Baginska et al., (13) the frequencies of pufa in 5-and 7-year-olds were reported to be $43.4 \%$ (with a mean value of $2.20 \pm 3.43$ ) and $72.4 \%$ (with a mean value of 2.44 \pm 2.22 ), respectively. Monse et al. (2) reported a frequency of $85 \%$ of pufa. Leal et al. (25) and Figueiredo et al. (6) reported a frequency value similar to ours (approximately 25\%). Differences between our findings and those of previous studies may also be attributed to examiner effects. In our study, all examinations were performed by an experienced pedodontist. In addition, a good kappa coefficient indicated good intra-examiner reliability.

It should be noted that in all studies using the PUFA/pufa index, $(2,6,12,22)$ most teeth with clinical consequences of untreated caries were classified as $\mathrm{P} / \mathrm{p}$ code. Similarly, the $\mathrm{P} / \mathrm{p}$ was the most frequently reported component in our study ( $\mathrm{P}=3.5 \%$ and $\mathrm{p}=23.0 \%)$. Also, $0.8 \%$ and $5.7 \%$ of primary carious teeth had fistula and abscess, respectively. Out of the permanent teeth, $0.3 \%$ represented signs of dental abscess. Moreover, none of the subjects had oral mucosal ulcers due to untreated carious teeth. In studies conducted in the Philippines (2) and Nigeria, (12) the prevalences of dental infection (fistula and abscess) in primary teeth were reported to be $18 \%$ and $28 \%$, respectively.

Our findings showed a significant association between 
Table 3. Comparison of Indices in Terms of BMI (Under-Weight Versus Normal)

\begin{tabular}{|cc}
\hline Index & BMI \\
\hline Prevalence (No) & $<0.001^{\mathrm{b}}$ \\
\hline dmft & $0.226^{\mathrm{b}}$ \\
\hline DMFT & $0.195^{\mathrm{b}}$ \\
\hline dmft + DMFT & $0.001^{\mathrm{b}}$ \\
\hline pufa & $0.819^{\mathrm{b}}$ \\
\hline PUFA & $0.002^{\mathrm{b}}$ \\
\hline pufa + PUFA & \\
\hline Severity (Mean) & $0.001^{\mathrm{c}}$ \\
\hline dmft & $0.179^{\mathrm{c}}$ \\
\hline DMFT & $<0.001^{\mathrm{c}}$ \\
\hline dmft + DMFT & $0.002^{\mathrm{c}}$ \\
\hline pufa & $0.670^{\mathrm{c}}$ \\
\hline PUFA & $0.004^{\mathrm{c}}$ \\
\hline pufa + PUFA & \\
\hline${ }^{\mathrm{a}}$ Signisher's Exact Test. & \\
\hline Mann-Whitney U Test. & \\
\hline
\end{tabular}

BMI (normal and under-weight) and the overall prevalence and mean value of untreated dental caries. A similar association was also found for pufa. The relationship of BMI and oral health has been extensively studied worldwide, and controversial results have been reported. The association of BMI with dental caries is complex and is influenced by several factors. Some studies have confirmed the association of BMI and dental caries $(1,14)$. However, the interpretation of these results must be undertaken with caution. We only analyzed the data of normal weight and underweight subjects. In addition to the impact of this, it should be noted that previous studies have used different criteria for classification of BMI. In Iran, no standard national criteria exist for growth assessment of children. Thus, differences in the reported results may be attributed to different growth patterns of children with the WHO standard criteria as well as variability in the statistical populations.

Monse et al. (2) and Benzian et al. (1) in the Philippines showed that children with untreated caries had a significantly lower than normal BMI. The results of the current study also show a significantly higher prevalence and severity of untreated dental caries in the primary teeth of under-weight children; this indicates that untreated dental caries have been neglected in the assessment of growth and development in children.

As expected, we found no significant difference in terms of the prevalence of untreated dental caries and their mean value between males and females; in line with our study, none of the previous studies have found gender differences in this regard.

Some developmental dental anomalies, such as enamel hypoplasia seen in hypophosphatemic rickets (26) may represent as untreated dental caries; so we excluded children who suffered from diseases which manifest inherited or environmental developmental dental defects.

In the PUFA/pufa index, there is no score pertaining to the severity of pain as the consequence of untreated dental caries. This drawback can be considered as one limitation of the index. In various studies pain parameter as the consequence of dental disease itself or the outcome of treatment intervention has been evaluated (27-29). However, in PUFA/pufa index which is only relied on objective signs, the subjective parameters such as pain and discomfort have not been considered.

Our study had some limitations. Unequal distribution of children in BMI groups was a limitation of our study; for this reason, we could not assess the prevalence and severity of PUFA/pufa in over-weight and obese children. Hence, observational longitudinal studies using PUFA/pufa in larger statistical populations and with a wider age range of subjects are recommended. However, our study provided basic information in a sample of Iranian children and calls for timely dental care services.

\subsection{Conclusion}

The current study provided some information regarding the prevalence of untreated dental caries, which have not been previously reported for Iranian children; 30.0\% of our study population had untreated dental caries. A great portion of the pufa/pufa score is was allocated to $\mathrm{P} / \mathrm{p}$. No significant difference was found between males and females with regard to the prevalence and severity of untreated dental caries. A significant association was found between BMI and the overall prevalence and mean value of untreated dental caries, as well as between BMI and the prevalence and mean value of pufa.

\section{Footnotes}

Authors' Contribution: Nahid Ramazani defined the intellectual content, designated the study protocol, examined the subjects, and analyzed the data. Sara Rezaei selected the subjects randomly and registered them for study participation. The final manuscript was critically reviewed and edited by both authors.

Funding/Support: This article was derived from a general dentistry dissertation approved by the deputy of Research and technology of Zahedan University of Medical Sciences 
(No. 5936). Herein, the deputy is appreciated for financial supports.

\section{References}

1. Benzian H, Monse B, Heinrich-Weltzien R, Hobdell M, Mulder J, van Palenstein Helderman W. Untreated severe dental decay: a neglected determinant of low Body Mass Index in 12-year-old Filipino children. BMC Public Health. 2011;11:558. doi: 10.1186/1471-2458-11-558. [PubMed: 21752286].

2. Monse B, Heinrich-Weltzien R, Benzian H, Holmgren C, van Palenstein Helderman W. PUFA-an index of clinical consequences of untreated dental caries. Community Dent Oral Epidemiol. 2010;38(1):77-82. doi: 10.1111/j.1600-0528.2009.00514.x. [PubMed: 20002630].

3. Alkarimi HA, Watt RG, Pikhart H, Jawadi AH, Sheiham A, Tsakos G. Impact of treating dental caries on schoolchildren's anthropometric, dental, satisfaction and appetite outcomes: a randomized controlled trial. BMC Public Health. 2012;12:706. doi: 10.1186/1471-2458-12706. [PubMed: 22928903].

4. Monse B, Duijster D, Sheiham A, Grijalva-Eternod CS, van Palenstein Helderman W, Hobdell MH. The effects of extraction of pulpally involved primary teeth on weight, height and BMI in underweight Filipino children. A cluster randomized clinical trial. BMC Public Health. 2012;12:725. doi:10.1186/1471-2458-12-725. [PubMed: 22938147]

5. Ramazani N,Ahmadi R, Daryaeian M. Oral and dental laser treatments for children: applications, advantages and considerations. J Lasers Med Sci. 2012;3(1):44.

6. Figueiredo MJ, de Amorim RG, Leal SC, Mulder J, Frencken JE. Prevalence and severity of clinical consequences of untreated dentine carious lesions in children from a deprived area of Brazil. Caries Res. 2011;45(5):435-42. doi: 10.1159/000330531. [PubMed: 21860241].

7. Gradella CM, Bernabé E, Bönecker M, Oliveira LB. Caries prevalence and severity, and quality of life in Brazilian 2- to 4-year-old children. Community Dent Oral Epidemiol. 2011;39(6):498-504.

8. Sadeghi M, Lynch CD, Arsalan A. Is there a correlation between dental caries and body mass index-for-age among adolescents in Iran?. Com munity Dent Health. 2011;28(2):174-7. [PubMed: 21780359].

9. Eslamipour F, Borzabadi-Farahani A, Asgari I. The relationship between aging and oral health inequalities assessed by the DMFT index. Eur J Paediatr Dent. 2010;11(4):193-9. [PubMed: 21250771].

10. Ramazani N, Ahmadi R, Ramazani M, Daryaeian M, Saeidi AH. Prevalence of semi-erupted first permanent molar occlusal caries and evaluation of related clinical factors in children. ZJRMS. 2013;15(1):52-4.

11. Ahmadi R, Ramazani N, Nourinasab R. Molar incisor hypomineralization: a study of prevalence and etiology in a group of Iranian children. Iran J Pediatr. 2012;22(2):245-51. [PubMed: 23056894].

12. Oziegbe EO, Esan TA. Prevalence and clinical consequences of untreated dental caries using PUFA index in suburban Nigerian school children. Eur Arch PaediatrDent. 2013;14(4):227-31. doi:10.1007/s40368013-0052-5. [PubMed: 23780656].

13. Baginska J, Rodakowska E, Wilczynska-Borawska M, Jamiolkowski J. Index of clinical consequences of untreated dental caries (pufa) in primary dentition of children from north-east Poland. Adv Med Sci. 2013;58(2):442-7. doi: 10.2478/v10039-012-0075-x. [PubMed: 23793065].

14. Malek Mohammadi T, Hossienian Z, Bakhteyar M. The association of body mass index with dental caries in an Iranian sample of children. J Oral Health Oral Epidemiol. 2012;1(1):29-35.
15. Ramazani N. Child dental neglect: a short review. Int J High Risk Behav Addict. 2014;3(4):21861. doi: 10.5812/ijhrba.21861. [PubMed: 25741483].

16. Ramazani N, Sadeghi P. Bacterial leakage of mineral trioxide aggregate, calcium-enriched mixture and biodentine as furcation perforation repair materials in primary molars. Iran Endod J. 2016;11(3):214-8. doi:10.7508/iej.2016.03.013. [PubMed: 27471534].

17. Ramazani N, Poureslami HR, Ahmadi R, Ramazani M. Early childhood caries and the role of pediatricians in its prevention. Iran J Pediatr Soc. 2010;2(2):47-52.

18. Ahmadi R, Ramazani N, Nourelahi M. A Comparison of the antiplaque effectiveness of Meridol (AmineFluoride/ Stannous Fluoride) and Irsha Kids mouth rinses in 7-9 year-old children. ZJRMS. 2013;15(1):10-4.

19. Murthy AK, Pramila M, Ranganath S. Prevalence of clinical consequences of untreated dental caries and its relation to dental fear among 12-15-year-old schoolchildren in Bangalore city, India. Eur Arch Paediatr Dent. 2014;15(1):45-9. doi: 10.1007/s40368-013-0064-1. [PubMed: 23835899].

20. Ramazani N, Mohammadi A, Amirabadi F, Ramazani M, Ehsani F. In vitro investigation of the cleaning efficacy, shaping ability, preparation time and file deformation of continuous rotary, reciprocating rotary and manual instrumentations in primary molars. J Dent Res Dent Clin Dent Prospects. 2016;10(1):49-56. doi: 10.15171/joddd.2016.008. [PubMed: 27092215].

21. Ramazani N. Different aspects of general anesthesia in pediatric dentistry: A review. Iran J Pediatr. 2016;26(2):2613. doi: 10.5812/ijp.2613. [PubMed: 27307962]

22. Shanbhog R, Godhi BS, Nandlal B, Kumar SS, Raju V, Rashmi S. Clinical consequences of untreated dental caries evaluated using PUFA in dex in orphanage children from India. J Int Oral Health. 2013;5(5):1-9. [PubMed: 24324297].

23. Ismail AI, Sohn W, Tellez M, Amaya A, Sen A, Hasson H, et al. The International Caries Detection and Assessment System (ICDAS): an integrated system for measuring dental caries. Community Dent Oral Epidemiol. 2007;35(3):170-8. doi:10.1111/j.1600-0528.2007.00347.x. [PubMed: 17518963].

24. Baginska J, Stokowska W. Pulpal involvement-roots-sepsis index: a new method for describing the clinical consequences of untreated dental caries. Med Princ Pract. 2013;22:555-60. doi: 10.1159/000354193. [PubMed: 23949116].

25. Leal SC, Bronkhorst EM, Fan M, Frencken JE. Untreated cavitated dentine lesions: impact on children's quality of life. Caries Res 2012;46(2):102-6. doi: 10.1159/000336387. [PubMed: 22398411].

26. Ramazani N. Hypophosphatemic rickets and its dental significance. Iran J Pediatr. 2013;23(6):714.

27. Ramazani M, Hamidi MR, Moghaddamnia AA, Ramazani N, Zarenejad N. The prophylactic effects of zintoma and ibuprofen on postendodontic pain of molars with irreversible pulpitis: A randomized clinical trial. Iran Endod J. 2013;8(3):129-34

28. Goodwin M, Sanders C, Davies G, Walsh T, Pretty IA. Issues arising following a referral and subsequent wait for extraction under general anaesthetic: impact on children. BMC Oral Health. 2015;17(15):3. doi: 10.1186/1472-6831-15-3.

29. Staman NM, Townsend JA, Hagan JL. Observational study: discomfort following dental procedures for children. Pediatr Dent. 2013;35(1):52 doi:10.1186/1472-6831-15-3. 